\title{
Evaluation of relation between air pollution and hepatic encephalopathy exacerbation
}

\begin{abstract}
Background: To evaluate relation between air pollution and rate and duration of hospital admission due to hepatic encephalopathy as a major complication of liver cirrhosis.

Methods: In this retrospective study, during a 10 months period, the number and average duration of hospitalization of patients admitted in GI ward of a referral center due to hepatic encephalopathy were recorded in an industrial capital city. Concomitantly the level of 4 major air pollutants including $\mathrm{SO}_{2}, \mathrm{CO}, \mathrm{NO}_{2}$ and $\mathrm{O}_{3}$ measured and the correlation between severity of hepatic encephalopathy and air pollution determined by Pearson correlation coefficient.

Results: Average number of admission was 5 to 6 patients per month (1-10). The average duration of hospitalization was 7.6 days (3-19). After comparison of average concentration of 4 major air pollutants with rate of hepatic encephalopathy, there was a relation, between $\mathrm{O}_{3}$ concentration and duration of admissions $(\mathrm{P}=0.048$, correlation coefficient 0.636$)$ and also a non-significant relation between $\mathrm{O}_{3}$ concentration and number of admissions $(\mathrm{P}=0.78$, correlation coefficient 0.58 ). DATA analysis did not reveal any significant relation between $\mathrm{SO}_{2}, \mathrm{NO}_{2}$ and $\mathrm{CO}$ and the rate and duration of admission due to hepatic encephalopathy $(\mathrm{P}>0.05)$.
\end{abstract}

Conclusion: It seems that $\mathrm{O}_{3}$ as one of the major air pollutants can aggravates course of hepatic encephalopathy. This issue should further be clarified in future studies.
Volume 5 Issue 3 - 2016

\author{
Pezhman Alavinejad, Seyed Ali Mard, Eskandar \\ Hajiani, Simin Mojahedin, Sadegh Larki \\ Department of Gastroenterology and Hepatology, Ahvaz \\ Jundishapur University of Medical Sciences, Iran
}

\begin{abstract}
Correspondence: Pezhman Alavinejad, Assistant professor of Gastroenterology and Hepatology, Research Center for Infectious Diseases of Digestive System, Ahvaz Jundishapur University of Medical Sciences, Ahvaz, Iran, Tel +98 916 | | | 5880, Fax+986132921839 Email pezhmanalavinejad@gmail.com
\end{abstract}

Received: July 26, 2016 | Published: September 22, 2016

\section{Introduction}

Hepatic encephalopathy (HE) or Porto systemic encephalopathy is a complicated neuro-pschychatric syndrome which could be over ride on any advanced liver disorder or produce after introduction of extensive collateral connection between systemic and visceral circulation. ${ }^{1,2}$ and as an important event in the natural history of cirrhosis, affects subsequent survival of patients. ${ }^{3}$ It has been postulated that inadequate hepatic elimination of nitrogenous compounds and neurotoxin byproducts of GI tract metabolism, accumulation of inflammatory cytokines, benzodiazepine-like compounds and manganese deposition result in hepatic encephalopathy. ${ }^{1,4,5}$

Clinical characteristics of hepatic encephalopathy range from mild changes in cognition to profound coma and include disturbance of high level intellectual and mental performance such as intelligence and personality, disorientation, dementia, inability to copy simple tasks (apraxia), neuromuscular dysfunction (flapping tremor, myoclonus, asterixis) and/or rarely a progressive paraplegia and Parkinson like syndrome. ${ }^{6,7}$

The action of ammonia, inflammatory cytokines, benzodiazepines and hyponatraemia integrates at the level of astrocyte swelling and oxidative stress. Recent studies have demonstrated that air pollution components reach the brain and activation of microglial cells in the brain during liver failure and confirmed a central neuroinflammatory response. This explains why heterogeneous clinical conditions can precipitate HE episodes.$^{8-10}$

One of the environmental factors that directly affect inflammatory cascade in body and trigger production and release of inflammatory cytokines such as IL-8, IL-6, and TNF $\alpha$ is air pollution. ${ }^{11-14}$ Air pollution and in particular burning fossil-fuels related pollutants which contains a large amount of nitrogen oxides and levitate particles have been problematic in recent decades especially in urban and industrial communities as a public health hazard. ${ }^{10,15-19}$ In fact the risk factors of industrialization were not fully evaluated and in this retrospective study, we have evaluated any potential effect of air pollution as a trigger factor on the rate and duration of hospital admission due to hepatic encephalopathy among a referral center in a capital industrial city of Khuzestan province.

\section{Materials and methods}

In this retrospective cross sectional survey, by evaluating the records of Ahvaz aerology stations and air pollution committee of Ahvaz Jundishapur University, the DATA about 4 major air pollutants including $\mathrm{CO}, \mathrm{SO}_{2}, \mathrm{O}_{3}$ and $\mathrm{NO}_{2}$ and their average concentration during a ten months period since May 2012 to February 2013 gathered and by refer to archive of Imam Hospital as a referral center, all of the admission files due to hepatic encephalopathy during the same period investigated. Inclusion criteria included any admission in GI ward due to hepatic encephalopathy and exclusion criteria was any history of head trauma or inadvertent sedative consumption. Then by using Pearson Correlation Coefficient and analyze by SPSS 19 software, any relation between increasing air pollution and rate and duration of hospital stay, evaluated.

\section{Results}

Overall in a 10 months period from May 2012 to February 2013, there were 57 cases of admission due to hepatic encephalopathy (average 5 to 6 cases per month) of them $46(80.7 \%)$ were male. 
The highest rate of admission recorded on May, June (10 cases of hepatic encephalopathy) and November ( 8 cases) while the least rate of admission due to encephalopathy recorded on February (1 case) (Figure 1). Average duration of admission was 7.6 days with maximum hospital stay about 19 days in May. In the same period, the concentration of 4 major air pollutants including $\mathrm{CO}, \mathrm{NO}_{2}, \mathrm{SO}_{2}$ and $\mathrm{O}_{3}$ measured in multiple meteorology stations around Ahvaz City as the capital of Khuzestan province and then the median concentration of each pollutant calculated. For $\mathrm{CO}$, the least concentration recorded in early November (35.3 PPM) while the highest level was seen on July and October (average 101 \& 103 PPM respectively). The least concentration of $\mathrm{NO}_{2}$ recorded in May (0.6 PPM) and its highest level measured in July, October and December ( $>5$ PPM). The lowest and highest concentration of $\mathrm{SO}_{2}$ recorded in May (0.1 PPM) and January (0.8 PPM) respectively while minimum and maximum concentration of $\mathrm{O}_{3}$ recorded in February (1.3 PPM) and May (3.3 PPM) (Figure 2). When the rate and duration of admission due to hepatic encephalopathy compared with concentration of these air pollutants, there was a relation, between $\mathrm{O}_{3}$ concentration and duration of admissions $(\mathrm{P}=0.048$, correlation coefficient 0.636$)$ and also a non-significant relation between $\mathrm{O} 3$ concentration and number of admissions ( $\mathrm{P}=0.78$, correlation coefficient 0.58 ) (Figure 3 ). DATA analysis did not reveal any significant relation between $\mathrm{SO}_{2}$, $\mathrm{NO}_{2}$ and $\mathrm{CO}$ and the rate and duration of admission due to hepatic encephalopathy $(\mathrm{P}>0.05)$ (Table 1$)$.

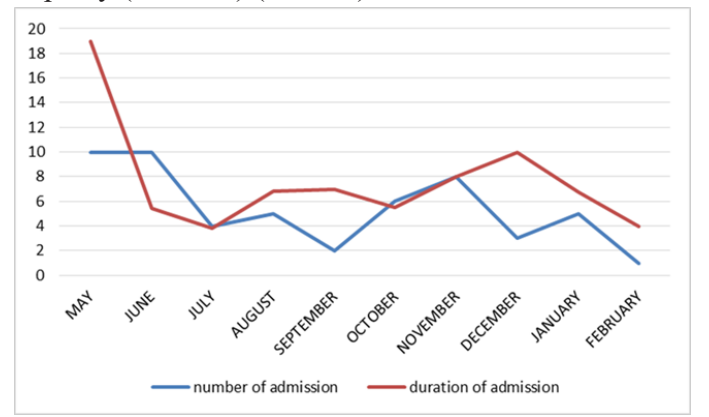

Figure I The rate and duration of hospital stay due to hepatic encephalopathy during a 10 months period.

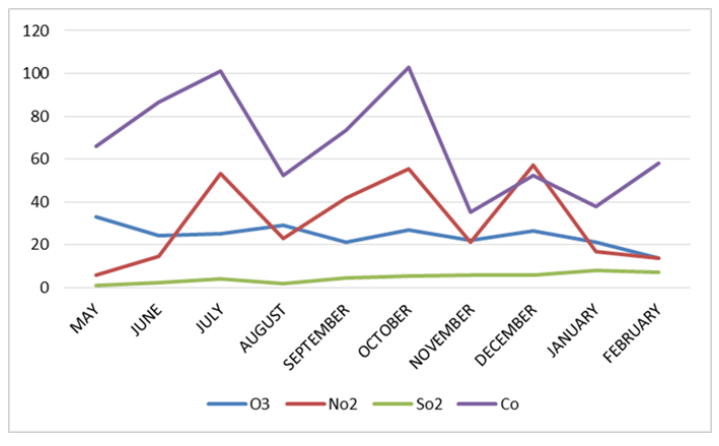

Figure 2 The concentration of 4 major air pollutants during a 10 months period based on PPM (PPM: part per million, the values of O3, No2 \& So2 multiply by 10).

\section{Discussion}

Hepatic encephalopathy (HE) includes a wide array of transient and reversible neurologic and psychiatric manifestations which develop in $50 \%$ to $70 \%$ of patients with cirrhosis as a poor prognostic indicator. ${ }^{20}$ Although HE is often triggered by an inciting event that results in a rise of the serum ammonia level, the precise underlying pathophysiologic mechanisms are not well understood. ${ }^{5}$ A number of factors have been implicated in the development of HE. These factors include production of neurotoxins, altered permeability of the bloodbrain barrier, and abnormal neurotransmission. The best-described neurotoxin involved in $\mathrm{HE}$ is ammonia, which is produced primarily in the colon, where bacteria metabolize proteins and other nitrogenbased products into ammonia. ${ }^{5,21}$

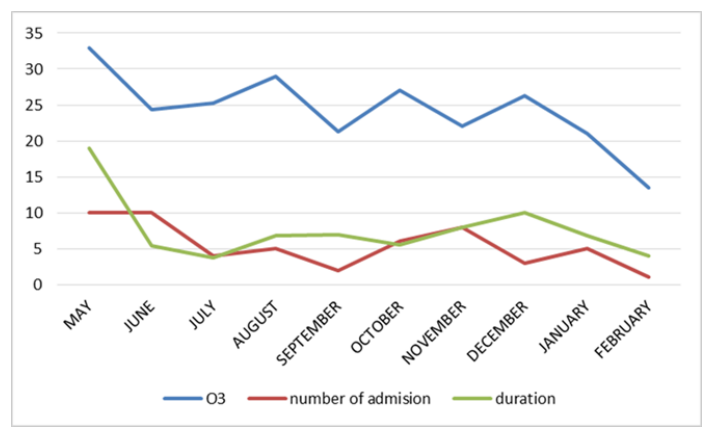

Figure 3 Relation between $\mathrm{O} 3$ concentration (PPM) and rate and duration of hospital admission due to hepatic encephalopathy.

Table I Relation between number and duration of admissions due to hepatic encephalopathy and 3 major air pollutants $\left(\mathrm{No}_{2}, \mathrm{So}_{2} \& \mathrm{CO}\right)$; Correlation is significant at the 0.05 level (2-tailed)

\begin{tabular}{lllll}
\hline & & $\mathrm{No}_{2}$ & $\mathrm{So}_{2}$ & $\mathbf{C O}$ \\
\hline \multirow{3}{*}{ Number } & Pearson Correlation & -0.447 & -0.565 & 0.070 \\
& Sig. (2-tailed) N & 0.195 & 0.089 & 0.848 \\
& & 10 & 10 & 10 \\
\multirow{4}{*}{ Duration } & Pearson Correlation & -0.324 & -0.449 & -0.254 \\
& Sig. (2-tailed) N & 0.361 & 0.193 & 0.478 \\
& & 10 & 10 & 10 \\
\hline
\end{tabular}

One of the most important environmental factors that has been problematic in recent decades especially among urban societies and could raise the serum level of inflammatory cytokines by affecting gut microbiota function is air pollution. ${ }^{18,22-25}$ Oral route accounts for much of the exposure to air pollutants and human studies have shown that larger particles are quickly cleared from the lungs and transported to the intestinal tract by mucociliary clearance. ${ }^{26}$ In this way, a large fraction of inhaled pollutants will be ingested and rapidly enter the intestine. ${ }^{27}$ In the bowel plausible mechanisms that mediating the effects of air pollutants include direct effects on epithelial cells, triggering systemic inflammation and immune activation, and modulation of the intestinal microbiota. ${ }^{18} \mathrm{~A}$ Canadian research group calculated the daily concentrations of ozone $\left(\mathrm{O}_{3}\right), \mathrm{NO}_{2}, \mathrm{SO}_{2}, \mathrm{CO}$, and particles $<10$ (PM10) or $<2.5$ (PM2.5) $\mu \mathrm{m}$ and by case crossover study design estimated the odds ratio of these air pollutants on colonic motility and visceral abdominal pain. Findings of this study showed an increased risk of non-specific abdominal pain among individuals aged 15 to 24 years and also colonic transit was delayed following chronic but not acute exposure with the pollutants. ${ }^{28}$

It has been shown that $\mathrm{O}_{3}$ can induce inflammation in airways by affecting the innate immune signaling, impairment of antibacterial host defense and disruption of epithelial barrier. ${ }^{29,30}$ Experimental studies results show that, epithelial cells produce increased amounts of IL-6, IL-8, or fibronectin following ozone exposure and both IL-6 and fibronectin are secreted vectorially. ${ }^{31}$ Animal studies suggesting that inflammation-associated alterations may contribute to cognitive impairment in hepatic encephalopathy. ${ }^{32}$ Higher levels of TNF $\alpha$ and IL-6 are detectable in the serum of patients with fulminant hepatitis and cirrhosis. ${ }^{33,34}$ and inflammatory cytokines in patients with infections and liver disease could influence brain function at different 
levels including the cerebral endothelial cell and Astrocytes. ${ }^{35}$ Our finding revealed a relation between Ozone concentration and hepatic encephalopathy severity which further support the potential role of inflammatory cytokines on brain function among cirrhotics although our study has some limitation. The current study is retrospective and cannot account for unmeasured confounders, such as diet, time spent outdoor activities and occupation and also we did not measure the serum level of inflammatory cytokines such as TNF $\alpha$ and IL-6. Another limitation is the focus on exposure to air pollution immediately before or during the outcome while long-term exposures are more likely to contribute to chronic illnesses such as hepatic encephalopathy. While these limitations necessitate a cautious interpretation of findings, they should serve to emphasize the need for further evaluation about the effects of pollutants on the course of chronic liver diseases and especially hepatic encephalopathy.

\section{Acknowledgments}

None.

\section{Conflicts of interest}

The authors declare no conflicts of interest.

\section{References}

1. Ferenci P, Lockwood A, Mullen K, et al. Hepatic encephalopathydefinition, nomenclature, diagnosis, and quantification: final report of the working party at the 11th World Congresses of Gastroenterology, Vienna, 1998. Hepatology. 2002;35(3):716-721.

2. Blei AT, Córdoba J. Hepatic encephalopathy. Am J Gastroenterol 2001;96(7):1968.

3. Stewart CA, Malinchoc M, Kim W, et al. Hepatic encephalopathy as a predictor of survival in patients with end-stage liver disease. Liver Transpl. 2007;13(10):1366-1371.

4. Sundaram V, Shaikh OS. Hepatic encephalopathy: pathophysiology and emerging therapies. Med Clin North Am. 2009;93(4):819-836.

5. Dbouk N, McGuire BM. Hepatic encephalopathy: a review of its pathophysiology and treatment. Curr Treat Options Gastroenterol. 2006;9(6):464-474

6. Amodio P, Montagnese S, Gatta A, et al. Characteristics of minimal hepatic encephalopathy. Metab Brain Dis. 2004;19(3-4):253-267.

7. Dhiman RK, Chawla YK. Minimal hepatic encephalopathy. Indian $J$ Gastroenterol. 2009;28(1):5-16.

8. Häussinger D, Schliess F. Pathogenetic mechanisms of hepatic encephalopathy. Gut. 2008;57(8):1156-1165.

9. Butterworth RF. Hepatic encephalopathy: a central neuroinflammatory disorder? Hepatology. 2011;53(4):1372-1376.

10. Block ML, Calderón Garcidueñas L. Air pollution: mechanisms of neuroinflammation and CNS disease. Trends Neurosci. 2009;32(9):506516.

11. Nel A. Air pollution-related illness: effects of particles. Science. 2005;308(5723):804-806.

12. Carter JD, Ghio AJ, Samet JM, et al. Cytokine production by human airway epithelial cells after exposure to an air pollution particle is metaldependent. Toxicol Appl Pharmacol. 1997;146(2):180-188.

13. Becker S, Mundandhara S, Devlin RB, et al. Regulation of cytokine production in human alveolar macrophages and airway epithelial cells in response to ambient air pollution particles: further mechanistic studies. Toxicol Appl Pharmacol. 2005;207(2 Suppl): 269-275.

14. Chuang KJ, Chan CC, Su TC, et al. The effect of urban air pollution on inflammation, oxidative stress, coagulation, and autonomic dysfunction in young adults. Am J Respir Crit Care Med. 2007;176(4):370-376.

15. Ayres SM, Evans RG, Buehler ME. Air pollution: a major public health problem. CRC Crit Rev Clin Lab Sci. 1972;3(1):1-40.

16. Künzli N, Kaiser R, Medina S, et al. Public-health impact of outdoor and traffic-related air pollution: a European assessment. Lancet. 2000;356(9232):795-801.

17. Pope III CA, Dockery DW. Health effects of fine particulate air pollution: lines that connect. J Air Waste Manag Assoc. 2006;56(6):709-742.

18. Beamish LA, Osornio Vargas AR, et al. Air pollution: An environmental factor contributing to intestinal disease. J Crohns Colitis. 2011;5(4):279286

19. Barreiro de Acosta M, Castro AA, Souto R, et al. Emigration to western industrialized countries: A risk factor for developing inflammatory bowel disease. J Crohns Colitis. 2011;5(6):566-569.

20. Bustamante J, Rimola A, Ventura PJ, et al. Prognostic significance of hepatic encephalopathy in patients with cirrhosis. J Hepatol. 1999;30(5):890-895.

21. Shawcross DL, Damink SO, Butterworth RF, et al. Ammonia and hepatic encephalopathy: the more things change, the more they remain the same. Metab Brain Dis. 2005;20(3):169-179.

22. Clougherty JE, Levy JI, Kubzansky LD, et al. Synergistic effects of traffic-related air pollution and exposure to violence on urban asthma etiology. Environ Health Perspect. 2007;115(8):1140-1146.

23. Schwartz J, Slater D, Larson TV, et al. Particulate air pollution and hospital emergency room visits for asthma in Seattle. Am Rev Respir Dis. 1993;147(4):826-831.

24. Bell ML, McDermott A, Zeger SL, et al. Ozone and short-term mortality in 95 US urban communities, 1987-2000. Jama. 2004:292(19):23722378 .

25. Jerrett M, Burnett RT, Ma R, et al. Spatial analysis of air pollution and mortality in Los Angeles. Epidemiology. 2005;16(6):727-736.

26. Möller W, Häussinger K, Winkler Heil R, et al. Mucociliary and longterm particle clearance in the airways of healthy nonsmoker subjects. $J$ Appl Physiol. 2004;97(6):2200-2206.

27. Calderón Garcidueñas L, Franco Lira M, Torres Jardón R, et al. Pediatric respiratory and systemic effects of chronic air pollution exposure: nose, lung, heart, and brain pathology. Toxicol Pathol. 2007;35(1):154-162.

28. Kaplan GG, Szyszkowicz M, Fichna J, et al. Non-specific abdominal pain and air pollution: a novel association. PLoS One. 2012;7(10):e47669.

29. Cho HY, Zhang LY, Kleeberger SR. Ozone induced lung inflammation and hyper reactivity are mediated via tumor necrosis factor- $\alpha$ receptors. Am J Physiol Lung Cell Mol Physiol. 2001;280(3):L537-L546.

30. Hollingsworth JW, Kleeberger SR, Foster WM. Ozone and pulmonary innate immunity. Proc Am Thorac Soc. 2007;4(3):240-246.

31. Devlin RB, Mckinnon KP, Noah T, et al. Ozone-induced release of cytokines and fibronectin by alveolar macrophages and airway epithelial cells. Am J Physiol. 1994;266(6):L612-L619.

32. Cauli O, Rodrigo R, Piedrafita B, et al. Inflammation and hepatic encephalopathy: ibuprofen restores learning ability in rats with portacaval shunts. Hepatology. 2007;146(2):514-519.

33. Genesca J, Gonzalez A, Segura R, et al. Interleukin-6, nitric oxide, and the clinical and hemodynamic alterations of patients with liver cirrhosis. Am J Gastroenterol. 199;94(1):169-177.

34. Nagaki M, Iwai H, Naiki T, et al. High Levels of Serum Interleukin-10 and Tumor Necrosis Factor- $\alpha$ Are Associated with Fatality in Fulminant Hepatitis. J Infect Dis. 2000;182(4):1103-1108.

35. Blei AT. Infection, inflammation and hepatic encephalopathy, synergism redefined. J Hepatol. 2004;40(2):327-330. 